\title{
CAPACITY IMPROVEMENTS BASED ON DYNAMIC SIGNAL TIMING AT SIGNALIZED ROAD INTERSECTIONS USING GENETIC ALGORITHM
}

\author{
NAZA KHEDER GHANI ${ }^{1 *}$ and BOTAN MAJEED AL-HADAD ${ }^{* *}$ \\ *College of Engineering, Tishk International University, Kurdistan RegionIraq \\ *** Erbil Technology Institute, Erbil Polytechnic University, Kurdistan Region-Iraq
}

(Accepted for Publication: December 8, 2020)

\begin{abstract}
Due to lack of public transportation, economic growth and the rapid increase in the number of populations, the number of vehicles in Erbil city has recently increased dramatically. This increment caused congestion on the roads and posed most of the loads on the traffic intersections, which already have limited capacity. As the intersection volume increases, the degree of saturation (X) and delay increases and, as a consequence, the Level-of Service (LOS) decreases, leading to instability and platoon formation at the intersection approaches. One of the reasons of congestion at intersections is due to the fixed signal timing during the day, while the traffic volume at the intersections varies from one hour to another. This research suggests solutions to vehicle delays at intersections through using a Genetic Algorithm (GA) based optimization model to adjust the signal parameters to fit the real time traffic condition. The suggested model tries to optimize the cycle length besides the green time per phase for different time lags throughout the day. The results showed distinct and remarkable improvements in the intersection capacity with 2 to $13 \%$ along with an average delay of $28-64 \%$.
\end{abstract}

KEYWORDS: Genetic Algorithm; Traffic signalization; cycle length; average control delay; HCM2010; capacity

\section{INTRODUCTION}

T raffic signals at intersections plays a dramatic role in determining the overall performance level of an arterial system, but poorly designed traffic signals can result in unnecessary and excessive delays.

Traffic signals are used in urban networks for managing the movement of the vehicles, as well as to provide safety to the drivers, but it also has negative impacts on the intersections, such as delay and fuel emission. Delay is caused by congestion in the traffic intersection, which is a common issue in most developing cites (Pop, 2018; Kesur, 2009). To enhance the level of service (LOS) of an intersection the capacity needs to be maximized along with minimizing the average delay. Many researches obtained the optimal signal timing through Genetic Algorithm (GA), which is a category of evolutionary algorithm and sub-category of Artificial Intelligence (AI) which is invented by John Holland in the year 1975 at University of Michigan. This algorithm is based on the evolution theory of Charles Darwin, for instance it reproduces the evolution process and follows the natural selection process based on the fittest (Holland, 1975) .Foy et al., (1992) is considered the first ever research that used GA for the optimization of traffic signal timing. The study focused on green time optimization and the sequence of the phases of four intersections to reduce delay. Since then GA has become a common tool for traffic signal time optimization. 
It can be used for isolated and coordinated traffic intersection as well as for pretimed and actuated traffic mode. For actuated traffic mode, usually sensors or cameras are applied on the road to respond to the situations of the intersections. The use of GA has become common and practically in use since 2019 to optimize the green and red signal intervals of a cycle so that the average delay is minimum. As a fitness function for the GA model, field delay based on traffic queue was used on $\mathrm{T}$ - intersections and two-way intersections in Hardwar, India.(Sharma \& Kumar, 2019) Furthermore, through optimization in the signal timing, delay could be decreased by approximately $27 \%$ and capacity of the intersection could be increased up to $9 \%$ in K-shaped intersections in China. GA model was formulated for pretimed traffic signalization with a multi-objective signal timing, as well as various strategies have been used to compare the results, for instance Webster's Method, GA method based on timing optimization and GA method based on timing and sequence optimization. The optimum outcome could be provided by optimizing both, sequence and timing of the traffic. Through this optimization, the capacity of the intersections could be improved by $11 \%$. (Jiang, Tan, Zhang, Ran, \& Tang, 2019).

This paper is dedicated in researching the signal time optimization for a number of intersections in Erbil city by using Genetic Algorithm in MATLAB R2020a. The selected intersections were all isolated and in pretimed traffic mode. Traffic data were collected by using camera and after that the intersections were analyzed for their current situation and compared with the GA-based results.

The objective of this study is to improve and increase the capacity of the intersections, by optimizing the green time of each phase which, as a consequence, optimum cycle lengths are guaranteed. The outcome is based on minimum delay corresponding to reasonable Level-ofService (LOS) with improved capacity. In addition to that, it will improve the quality of the intersections and provide comfortability for the drivers. The economy and environment will be improved due to the reduction of fuel emissions. The mobility of the intersection as well as the safety in the intersection increases.

\section{METHODOLOGY AND MODEL FORMULATION}

In this study GA is used to optimize signal timing of intersection. The results are then compared with the current signal timing of the intersections in order to differentiate between the traffic statuses and evaluate the applied method. The current traffic conditions, including control delay, at the intersections are evaluated using HCM2010 method as described in the fitness function section.

\subsection{Genetic Algorithm Model Formulation}

Genetic algorithm is an optimization technic inspired by the evolution theory of natural selection and survival of the fittest by Charles Darwin. The process of genetic algorithm is to transform a set of strings called population, each having their own fitness value, into a new generation of population. The offspring are objected to the natural selection of Darwinian principle. During the transformation process, the population will go through the operations of crossover and mutation, the objective of this process is to form a new generation with better chromosomes than the older one, as well as with a better fitness function (Sivanandam \& Deepa, 2008). The basic flowchart of Genetic Algorithm is shown in Figure

(1). 


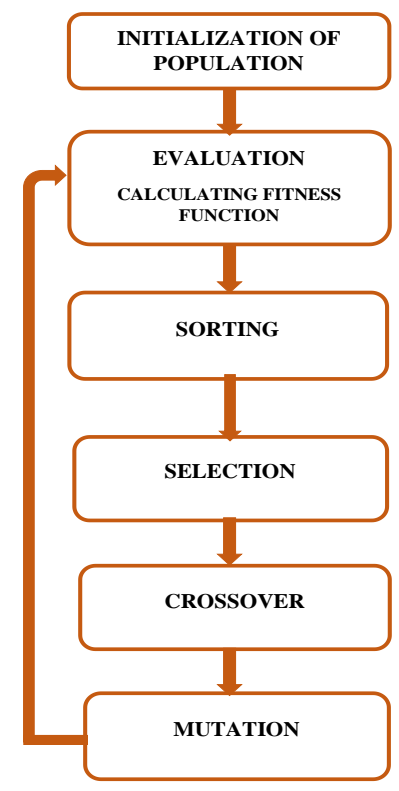

Fig. (1): Basic Flowchart of Genetic Algorithm

\subsubsection{Initialization of The Population}

First, solutions to the problem need to be represented in chromosomes. A set of chromosomes are called population or solution pool. For the initialization and representation of the population $\backslash$ chromosome, a set of constraints are combined in a string. These constraints are called genes. These genes are the description of results of a specific problem. Chromosome can be an array consisting of a sequence of binary numbers or it can consist of integer numbers (Sivanandam \& Deepa, 2008). In this study, the chromosome is a string or a one-dimensional array which consists of the total cycle length of the intersection, and the green time of each phase.

The process of genetic algorithm starts with a random set of population; therefore, for the initialization of the chromosomes or for generating the parent chromosomes, the following inputs are required:

1. Number of phases $(\mathrm{N})$ : the intersection approaches of Erbil city have the function of phase, which is typically four phases for a fourleg intersection. The phases sequence remains the same, since the population of Erbil get used to this mechanism and sequence.
2. Minimum and maximum cycle lengths: the cycle length should not exceed the practical allowable limits confined by minimum and maximum definition for the possible cycle length $(\mathrm{C})$ as follows:

$$
\mathrm{C}_{\min }<\mathrm{C}<\mathrm{C}_{\max }
$$

The limitation for minimum green time is set to be between $4 \mathrm{sec}-15 \mathrm{sec}$ (DECISION, 2015; Manual, 2010) depending on the traffic volume at that approach. In this study, the selected intersections are all crowded and therefore the minimum green signal time is set for 15 seconds. In addition to that, the maximum green signal time for a phase should be below $60 \mathrm{sec}$. Therefore, it can be stated that the proper value for $\mathrm{C}_{\min }$ and $\mathrm{C}_{\max }$ are 60 and 240 seconds respectively, nevertheless the average lost time of $4 \mathrm{sec}$ per phase has to be added to the green time, which makes the minimum and maximum cycle time range between 76 and $276 \mathrm{sec}$, respectively.

3. Number of operations: is the number of iterations that the program will apply the genetic algorithm operations, such as crossover and mutation, on the population.

4. Population size: is the number of chromosomes representing the population in a botan@epu.edu.iq 
generation. The population size is problem dependent. The more complex the problem the bigger the population size. Big population size provides diversity to the outcome and may guarantee optimum solution, but due to big population size the processing time required to generate the model will increase. A proper size needs to be selected based on test and result observations.

To completely initialize the parent chromosomes, the green time of each phase is randomized based on the generated cycle length
(C) and volume of the phase. This can be done by using the collected data obtained from the field. Through the collected data the characteristics of the intersection will be reflected to the distribution of the green time to each phase, as the green time will be distributed to each phase by the proportion of the volume of the phase to the total volume.

Then the chromosomes for a four-leg intersection is mapped with an appearance illustrated

Table (1): Appearance of the Chromosome

\begin{tabular}{llllll}
\hline Chromosomellndex & $\mathbf{1}$ & $\mathbf{2}$ & $\mathbf{3}$ & $\mathbf{5}$ & $\mathbf{4}$ \\
\hline Chromosome 1 & $\mathrm{C}_{1}$ & $\mathrm{~g}_{1}$ & $\mathrm{~g}_{2}$ & $\mathrm{~g}_{3}$ & $\mathrm{~g}_{4}$ \\
\hline Chromosome 2 & $\mathrm{C}_{2}$ & $\mathrm{~g}_{1}{ }^{*}$ & $\mathrm{~g}_{2}{ }^{*}$ & $\mathrm{~g}_{3}{ }^{*}$ & $\mathrm{~g}_{4}{ }^{*}$ \\
\hline
\end{tabular}

\section{Chromosome $=$}

Where, $\mathrm{C}$ is the cycle length of the intersection and $g_{1} \quad g_{2} \quad g_{3} \quad g_{4}$ are the green signal time with lost time included of each phase.

\subsubsection{Fitness Function (FF)}

For the evaluation of a chromosome (solution), the fitness function or even known as objective function can help evaluating the chromosome and their fitness to the problem. Pair of parents are selected using ranking based selection scheme (based on the fitness value) and each pair produces two offspring until the population is doubled. Then the parents are combined with the offspring and according to the fitness value of each chromosome, the fitter solutions are selected to go to the next generations while the poor ones should die off. In this study the fitness function is based on delay calculation based on HCM2010. Average delay is used as a measure of effectiveness for the selected intersections. After determining the delay, the Level-of Service (LOS) is determined since LOS is used as a measure of quality control (Garber \& Hoel, 2014). The fitness function is calculated as illustrated below:

\subsubsection{Delay Determination by Highway Capacity Manual 2010 (HCM2010)}

In HCM2010, control delay (d) consists of three delay components, which are uniform delay $\left(\mathrm{d}_{1}\right)$, incremental delay $\left(\mathrm{d}_{2}\right)$, along with initial queue delay $\left(d_{3}\right)$. Through Equation (1), the control delay can be determined according to HCM2010 for each vehicle in a specific lane group (Manual, 2010):

$$
\mathrm{d}=\mathrm{d}_{1}+\mathrm{d}_{2}+\mathrm{d}_{3}
$$

\subsubsection{Uniform Delay $\left(d_{1}\right)$}

Uniform delay deals with the effective green signal time (g) during one cycle length $(\mathrm{C})$ as well as with the degree of saturation $(\mathrm{X})$. The assumptions for the uniform delay are that there is uniform arrivals and the initial queue is equal to zero.

$$
d_{1}=\frac{0.5 C(1-g / C)^{2}}{1-[\min (1 . X) g / C]}
$$

\subsubsection{Incremental Delay $\left(d_{2}\right)$}

This type of delay is dealing with the nonuniform vehicle arriving at the intersection as well as with the over-saturated traffic flow condition.

$$
d_{2}=900 \mathrm{~T}\left[\left(\mathrm{X}_{\mathrm{A}}-1\right)+\sqrt{\left(\mathrm{X}_{\mathrm{A}}-1\right)^{2}+\frac{8 \mathrm{kIX} \mathrm{A}}{\mathrm{c}_{\mathrm{A}} \mathrm{T}}}\right]
$$


Where

$\mathrm{X}_{\mathrm{A}}=$ is the average volume-to-capacity of an approach.

$\mathrm{c}_{\mathrm{A}}=$ is the average capacity on an approach,

$\mathrm{T}=$ is the duration in hours of the analysis period (h)

$\mathrm{k}=$ is the factor which is dependent on the settings of the controller for the incremental delay. For pre-timed traffic signal control, the value of $\mathrm{k}$ will be 0.5 .

$\mathrm{I}=$ is the adjustment factor for upstream filtering. The value of I will be 1.0 for isolated intersection.

The third term $\left(d_{3}\right)$, which is the computed initial queue delay is equal to zero. The reason is due to assumption of having no initial queue in the GA model. Therefore, $\left(d_{3}\right)$ is neglected and not calculated.

The control delay for the entire intersection $\left(d_{I}\right)$ is computed by using Equation (4)

$$
\mathrm{d}_{\mathrm{I}}=\frac{\sum \mathrm{d}_{\mathrm{i}} \mathrm{v}_{\mathrm{i}}}{\sum \mathrm{v}_{\mathrm{i}}}
$$

Where

$\sum \mathrm{d}_{\mathrm{i}} \mathrm{v}_{\mathrm{i}}=$ Summation of the approach flow rate and approach control delay product

$\sum \mathrm{v}_{\mathrm{i}}=$ Summation of approach flow rate

After determining the delay, the LOS can be determined by using Table 2. This is done, in order to qualify the service of the intersection. For the GA-based optimization, the same evaluation parameter is used, which is the control delay of HCM2010. (Manual, 2010)

Table (2): Level of Service of Signalized Road Intersection

\begin{tabular}{ccc}
\hline Control Delay (s/ veh) & \multicolumn{2}{c}{ LOS by volume-to-capacity Ratio } \\
\cline { 2 - 3 } & $\leq 1.0$ & $>1.0$ \\
\hline$\leq 10$ & $\mathrm{~A}$ & $\mathrm{~F}$ \\
\hline$>10-20$ & $\mathrm{~B}$ & $\mathrm{~F}$ \\
\hline$>20-35$ & $\mathrm{C}$ & $\mathrm{F}$ \\
\hline $35-55$ & $\mathrm{D}$ & $\mathrm{F}$ \\
\hline$>55-80$ & $\mathrm{E}$ & $\mathrm{F}$ \\
\hline$>80$ & $\mathrm{~F}$ & $\mathrm{~F}$ \\
\hline
\end{tabular}

\subsubsection{Sorting and Selection based on Ranking}

The sorting mechanism plays an important role for determining the optimum solution. The chromosomes are going to be sorted according to their FF. The fittest solution will be listed at the top. So, if the fitness function is based on delay, the chromosome with minimum delay will be listed at the top.

Sort will list the high-ranked individuals at the top while low-ranked are discharged at the end of the population (Haupt \& Ellen Haupt, 2004). According to the ranked based selection mechanism, as used in this study, the best two chromosomes at the top are selected for breeding and so on.

\subsubsection{Crossover Operator}

Crossover is an important operator in Genetic
Algorithm, since the offspring are going to be produced by information exchange of the selected pair of chromosomes. In this study, crossover is applied on the genes that hold the green signal times of the chromosomes. During the process the corresponding green times are exchanged between the parent chromosomes. The exchange process has to be from the same phase, since the green time is generated according to the volume of the phase during initialization. Random- Proportion Crossover is used in this study. The method generates randomly a variable between zero and one, which is denoted as $\left(\mathrm{d}_{1}\right)$ after that it will calculate $d_{2}$ by subtracting $d_{1}$ from 1.00 , as shown below:

$$
\mathrm{d}_{1}=\operatorname{Rnd}[0-1] \text { and } \mathrm{d}_{2}=1-\mathrm{d}_{1}
$$


The summation of $d_{1}$ and $d_{2}$ are equal to 1.00 , these are the proportions used to produce two new offspring. The offspring of each pair of parents are produced by summing up the product of chromosome with the proportional ratios (d1 and $\mathrm{d} 2$ ), as illustrated below:

Offspring 1:

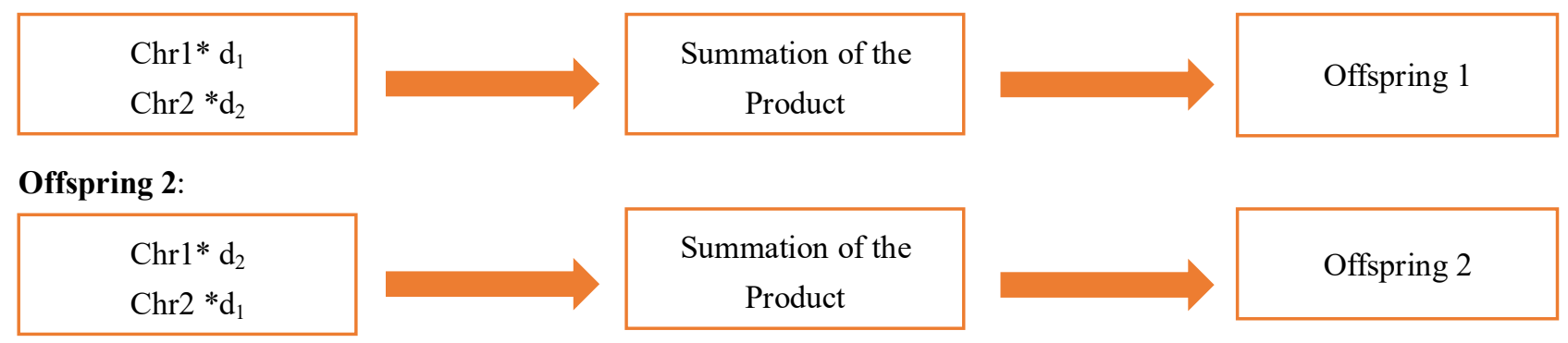

Fig. (2): Explanation of Random Proportion Crossover

\subsubsection{Mutation Operator}

Mutation is an operator to keep genetic diversity within the pool of individuals. Mutation alters the information of randomly selected gene/genes on a randomly selected chromosome constrained by mutation probability rate. The mutation method is sometimes problem specific depending on the nature of the problem (Whitley, 2001). In this research study the mutation method selects randomly a green time and adds randomly $\pm(5-15 \mathrm{sec})$. After that, a new cycle length is re-calculated, since the entire green signal time are altered during crossover and mutation if affected.

After several GA parameters analysis, an ideal combination that always provides the optimum result with guarantee and within the shortest processing time is illustrated in Table 3.

Table (3): Used parameter for Genetic Algorithm

\begin{tabular}{cc}
\hline & GA Parameter \\
\hline Number of Generation & 50 Generation \\
\hline Number of Population & 800 Population \\
\hline Crossover Probability & $100 \%$ \\
\hline Mutation Probability & $25 \%$ \\
\hline
\end{tabular}

\section{DATA COLLECTION AND ANALYSIS}

Two intersections are selected for this study in Erbil city. Erbil is the Capital of Kurdistan Region - Iraq. It has become one of the populated Cities in the region in which the population and number of vehicles have rapidly increased with time; the population increased from 0.73 Million in 2009 to 2 Million in 2019 (Governor's Office of Erbil, 2019), and the number of vehicles increased from 279,713 in 2009 to 762,309 in 2019 (Traffic Police
Directorate of Erbil, 2019). These results correspond to an annual average increase in population $17.4 \%$ and an average increase of vehicles by $17.25 \%$.

The first intersection, Shahidan Intersection, which is used for the study, is near to the bazaar located in the city center, were heavy vehicles are not allowed to use these roads during the daytime The other intersection is located on a commercial and industrial road, for many automobile and truck dealers as well as many Universities are located on this road, named 
Hadyab Intersection.

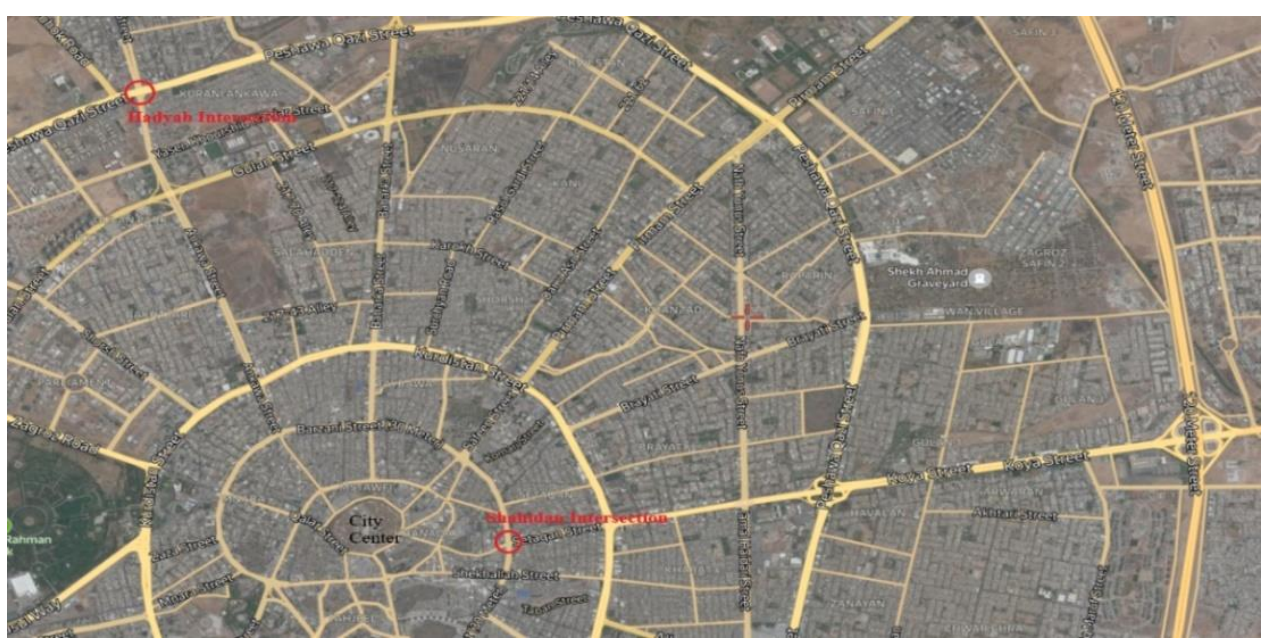

Fig. (3): Satellite Map of Erbil, with selected intersection (Google Maps)

For the data collection, video cameras were installed at the intersection to calculate various traffic characteristics of each phase, which include the volume of traffic and its composition since all types of vehicles have to be converted to passenger car by $\mathrm{PCU}$, average headway of each lane in order to determine the saturation flow rate. The other required data, such as geometric data and signal timing were determined at the field. The plan and the geometric data of the intersection are illustrated below:

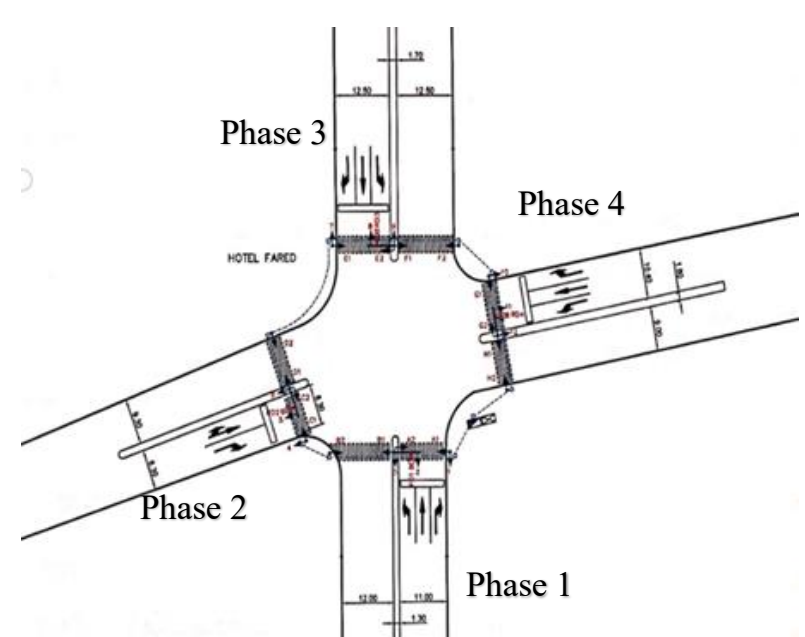

Fig. (4): Plan of Shahidan Intersection (Erbil Traffic Engineering Department)

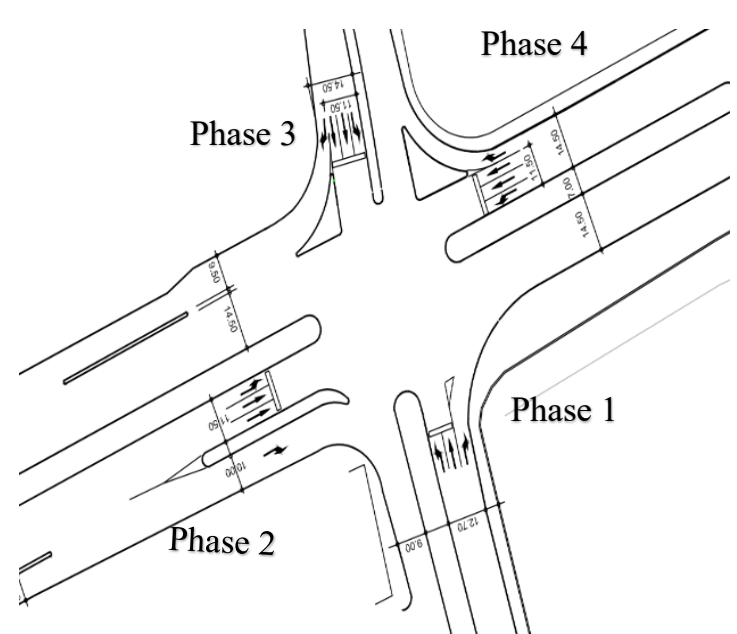

Fig. (5): Plan of Hadyab Intersection (Erbil Traffic Engineering Department 
Table (4): Geometric Data of the Intersection

\begin{tabular}{|c|c|c|c|c|c|c|c|}
\hline \multirow[b]{2}{*}{ Intersection } & \multicolumn{7}{|c|}{ Geometric Data of Shahidan Intersection on Barzani Namr Road } \\
\hline & Phase & Lane No. & $\begin{array}{c}\text { Flow } \\
\text { Direction }\end{array}$ & $\begin{array}{l}\text { Lane Width } \\
(\mathrm{m})\end{array}$ & $\begin{array}{l}\text { Approach } \\
\text { Width }(m)\end{array}$ & Grade \% & $\begin{array}{l}\text { Parking } \\
\text { Service }\end{array}$ \\
\hline \multirow{11}{*}{ 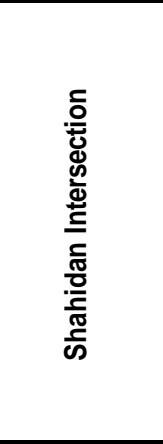 } & \multirow{3}{*}{1} & 1 & $\mathrm{~L}+\mathrm{T}$ & 4 & \multirow{3}{*}{12} & \multirow{3}{*}{-0.9} & \multirow{3}{*}{ No } \\
\hline & & 2 & $\mathrm{~T}$ & 4 & & & \\
\hline & & 3 & $T+R$ & 4 & & & \\
\hline & \multirow{2}{*}{2} & 1 & $L+T$ & 4.15 & \multirow{2}{*}{8.3} & \multirow{2}{*}{-2.5} & \multirow{2}{*}{ No } \\
\hline & & 2 & $R+T$ & 4.15 & & & \\
\hline & \multirow{3}{*}{3} & 1 & $L+T$ & 4 & \multirow{3}{*}{12} & \multirow{3}{*}{-0.9} & \multirow{3}{*}{ No } \\
\hline & & 2 & $\mathrm{~T}$ & 4 & & & \\
\hline & & 3 & $T+R$ & 4 & & & \\
\hline & \multirow{3}{*}{4} & 1 & $L+T$ & 3.47 & \multirow{2}{*}{6.94} & \multirow{3}{*}{-0.6} & \multirow{3}{*}{ No } \\
\hline & & 2 & $\mathrm{~T}$ & 3.47 & & & \\
\hline & & 3 & $\mathrm{R}$ & 3.46 & 3.46 & & \\
\hline \multirow{16}{*}{ 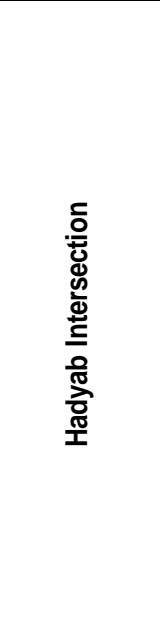 } & \multirow{4}{*}{1} & 1 & $L+T$ & 3.83 & \multirow{3}{*}{11.5} & \multirow{4}{*}{-0.4} & \multirow{4}{*}{ Yes } \\
\hline & & 2 & $L+T$ & 3.83 & & & \\
\hline & & 3 & $\mathrm{~T}$ & 3.83 & & & \\
\hline & & 4 & $\mathrm{R}$ & 3 & 3 & & \\
\hline & \multirow{4}{*}{2} & 1 & $L+T$ & 3.83 & \multirow{3}{*}{11.5} & \multirow{4}{*}{-0.3} & \multirow{4}{*}{ No } \\
\hline & & 2 & $L+T$ & 3.83 & & & \\
\hline & & 3 & $\mathrm{~T}$ & 3.83 & & & \\
\hline & & 4 & $\mathrm{R}$ & 3 & 3 & & \\
\hline & \multirow{3}{*}{3} & 1 & $L+T$ & 4.25 & \multirow{2}{*}{8.5} & \multirow{3}{*}{-0.4} & \\
\hline & & 2 & $T$ & 4.25 & & & No \\
\hline & & 3 & $\mathrm{R}$ & 4.2 & 4.2 & & \\
\hline & & 1 & $L+T$ & 3.83 & & & \\
\hline & & 2 & $L+T$ & 3.83 & 11.5 & & \\
\hline & 4 & 3 & $\mathrm{~T}$ & 3.83 & & 0.6 & No \\
\hline & & 4 & $\mathrm{~T}$ & 5 & 10 & & \\
\hline & & 5 & $\mathrm{R}$ & 5 & 10 & & \\
\hline
\end{tabular}

The study covers the time period from 7:00AM to 11:00 PM. This time period is considered the most critical lags and contain the most diverge traffic conditions. The peak traffic volume of the time groups of each intersection are demonstrated in Figure 6 and 7

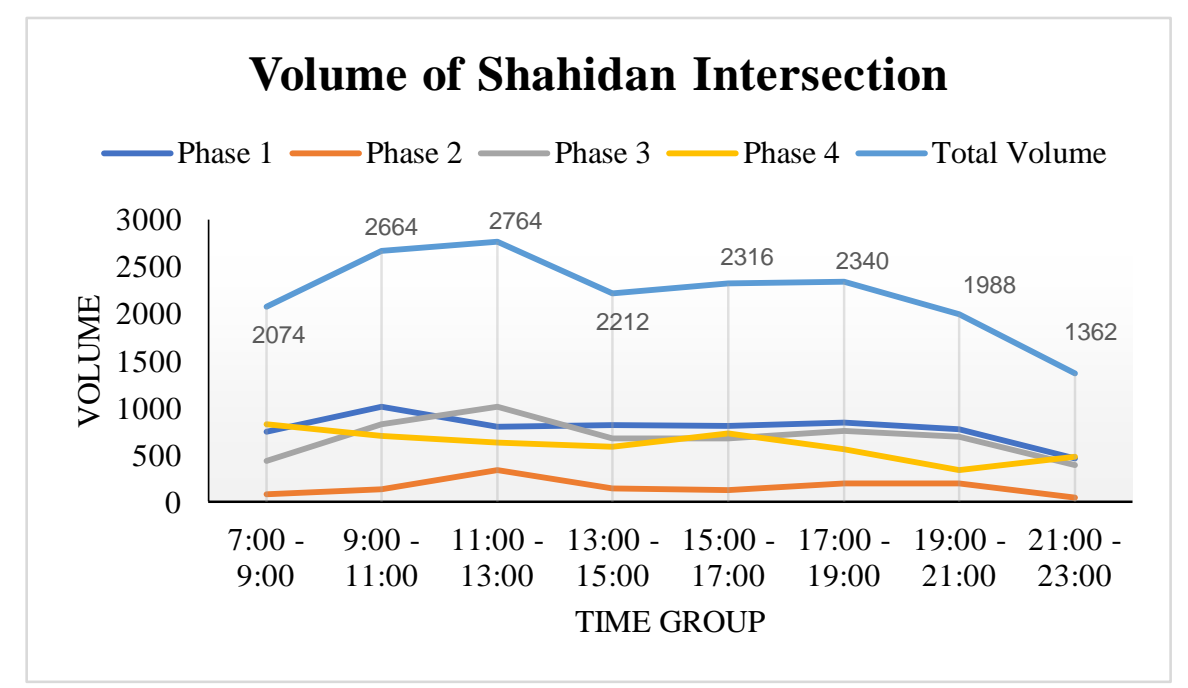

Fig. (6): Traffic Flow of Shahidan Intersection

naza.ghani@tiu.edu.iq; botan@epu.edu.iq

$714{ }^{1}$ Corresponding author: College of Engineering, Tishik International University, Kurdistan Region, Iraq. 


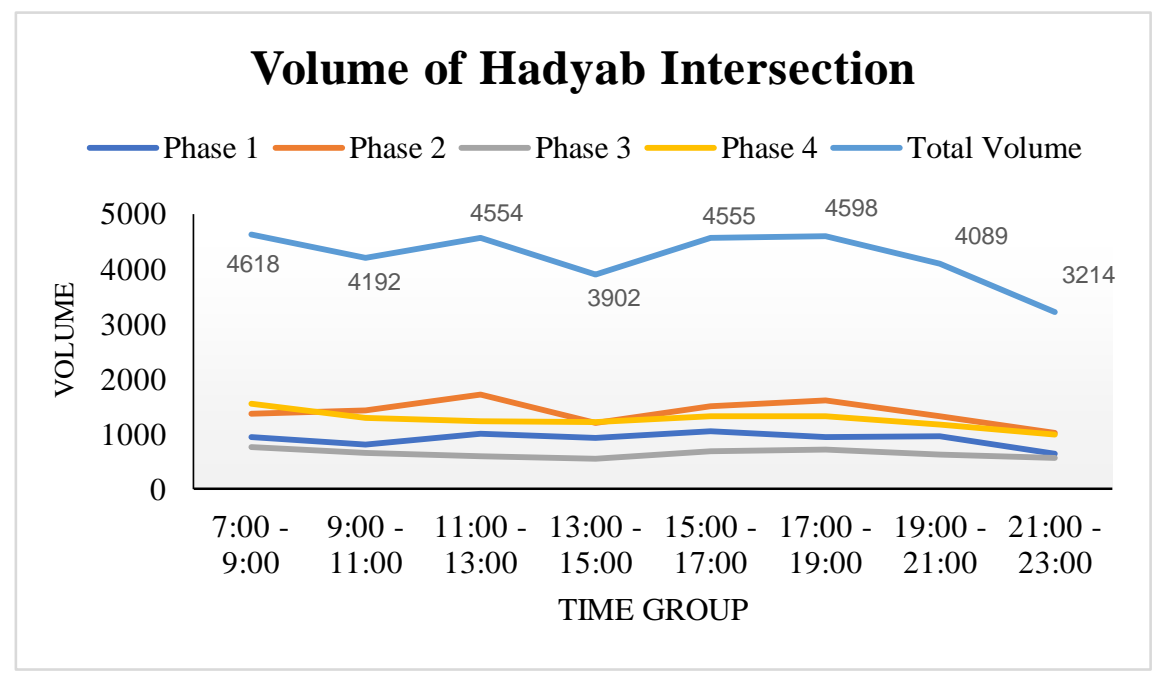

Fig. (7): Traffic Flow of Hadyab Intersection

The following figures graphically demonstrate the volume of the intersections, while the vertical axis represents the volume in (veh/hr) and the horizontal axis represents the time groups.The traffic flow of Shahidan Intersection, that is illustrated in Figure 6 does not exceed the $2800 \mathrm{veh} / \mathrm{hr}$. In addition to that, the geometry of intersection, which is represented in Table 4 are smaller compared to Hadyab intersection. While, the traffic flow in
Hadyab intersection is high, as it has a minimum flow rate of $3214 \mathrm{veh} / \mathrm{hr}$ late in the evening and up to $4618 \mathrm{veh} / \mathrm{hr}$ in the morning. The Traffic flow is approximately more than $4000 \mathrm{veh} / \mathrm{hr}$ during the day.

After obtaining the required data from the field and video camera, the saturation flow rate of each lane is adjusted according to the HC2010 and listed in Table 5 below:

Table (5): Adjusted Saturation Flow of the Intersection

\begin{tabular}{|c|c|c|c|c|c|c|c|c|c|c|c|c|c|}
\hline \multirow{2}{*}{$\begin{array}{c}\text { Intersection } \\
\text { Shahidan } \\
\text { Intersection }\end{array}$} & \multirow{2}{*}{$\begin{array}{c}\text { Phase } \\
\text { Lane } \\
\text { Number } \\
\end{array}$} & \multicolumn{3}{|c|}{ Phase 1} & \multicolumn{3}{|c|}{ Phase 2} & \multicolumn{2}{|c|}{ Phase 3} & \multicolumn{4}{|c|}{ Phase 4} \\
\hline & & 1 & \multicolumn{2}{|r|}{2} & \multicolumn{3}{|c|}{1} & 1 & 2 & \multicolumn{2}{|c|}{1} & \multicolumn{2}{|c|}{2} \\
\hline & & \multirow[b]{2}{*}{$\mathrm{L}+\mathrm{T}$} & \multirow{2}{*}{\multicolumn{2}{|c|}{$\mathrm{L}+\mathrm{T}$}} & \multirow{2}{*}{\multicolumn{3}{|c|}{$\mathrm{L}+\mathrm{T}$}} & & & \multirow{2}{*}{\multicolumn{2}{|c|}{$\mathrm{L}+\mathrm{T}$}} & \multirow{2}{*}{\multicolumn{2}{|c|}{$\mathrm{L}+\mathrm{T}$}} \\
\hline & Direction & & & & & & & $\mathrm{L}+\mathrm{T}$ & $\mathrm{L}+\mathrm{T}$ & & & & \\
\hline & $\begin{array}{c}\text { Saturation } \\
\text { Flow }\end{array}$ & 1723 & \multicolumn{2}{|r|}{1839} & \multicolumn{3}{|c|}{1720} & 1764 & 1693 & \multicolumn{2}{|c|}{1820} & \multicolumn{2}{|c|}{1703} \\
\hline \multirow{4}{*}{$\begin{array}{c}\text { Hadyab } \\
\text { Intersection }\end{array}$} & Lane & 1 & 2 & 3 & 1 & 2 & 3 & 1 & 2 & 1 & 2 & 3 & 4 \\
\hline & Number & & & & & & & & & & & & \\
\hline & Direction & $\mathrm{L}$ & $\mathrm{L}+\mathrm{T}$ & $\mathrm{T}$ & $\mathrm{L}$ & $\mathrm{L}+\mathrm{T}$ & $\mathrm{T}$ & $\mathrm{L}+\mathrm{T}$ & $\mathrm{T}$ & $\mathrm{L}$ & $\mathrm{L}$ & $\mathrm{T}$ & $\mathrm{T}$ \\
\hline & $\begin{array}{c}\text { Saturation } \\
\text { Flow }\end{array}$ & 1630 & 1519 & 1762 & 1450 & 1307 & 1620 & 1737 & 1737 & 1790 & 1790 & 1790 & 1790 \\
\hline
\end{tabular}

The data that are collected from field at the intersections' locations are analyzed and grouped and used as input to the GA based optimization model. Besides the GA parameters to process the optimization, the following field data are used for the analysis and the design of the intersection signal timing:

1.Summation of the lane groups of each phase, 
which represents the traffic volume of each phase.

2.Average saturation flow rate of each phase, which is adjusted according to HCM2010, illustrated in Table 5

3.Number of lanes of each approach

4.Average headway of the intersection

5.No of phases of the intersection, which is equal to the number of approaches. Since the drivers get used to this system and regulation.

\section{Lost time of each phase}

The most influential GA parameters that are critical to the obtained solutions are: population size, selection method, crossover method and probability rate, mutation method and probability rate, the form of fitness function, and termination criteria. As the GA is a complex combinatorial optimization technique, finding a tradeoff values to the parameters is a complex task. Therefore, in this study, more than five hundred of tests were made to test combinations of the parameters until coming up with a set of values that make the result global optimum.

The following section describes the result based on the parameters that produce global optimum. The GA fitness function of this research optimizes the cycle lengths and the green time of each phase based on minimizing the delay and maximizing the capacity at the intersection.

\section{RESULTS AND DISCUSSION}

The results are compared with the current condition of the intersections and there was an average reduction of delay by $42 \%$ and $51 \%$ at Shahidan and Hadyab Intersections, respectively. The LOS for each time lag is set based on the calculated delay as in Table 2 for the results illustrated in Table 6 and 7.

For each intersection the peak volumes vary according to the location of the intersection. Hadyab intersection is located on a commercial and industrial road in addition to the commuters who use the intersection daily for work, school and universities and therefore; the peaks are repetitive most of the times. The results from Table 6, shows that the LOS for this intersection could be improved to a better class. The resulted optimum signal timings from the GA model produced a reduction in delay from $31 \%$ to $55 \%$ during the varied time lags (peak and off-peak hours) of Hadyab intersection. In addition to that capacity of the intersection could be improved up to $11 \%$, which means that more than 500 vehicles.

The following optimum signal timings are obtained from the model:

Table (6): Signal timing of Hadyab Intersection before and after Optimization

\begin{tabular}{|c|c|c|c|c|c|c|c|c|c|c|c|c|c|c|c|c|c|c|}
\hline \multirow{3}{*}{ Time Group } & \multicolumn{5}{|c|}{ Current Time } & \multirow{3}{*}{$\begin{array}{c}\text { max. } \\
\text { Capacity } \\
\text { (veh) }\end{array}$} & \multirow{3}{*}{$\begin{array}{c}\text { avg. } \\
\text { Delay } \\
\text { (sec/veh) }\end{array}$} & \multirow{3}{*}{ LOS } & \multicolumn{5}{|c|}{ GA- based Design } & \multirow{3}{*}{$\begin{array}{c}\text { max. } \\
\text { Capacity } \\
\text { (veh) }\end{array}$} & \multirow{3}{*}{$\begin{array}{c}\text { avg. } \\
\text { Delay } \\
\text { (sec/veh) }\end{array}$} & \multirow{3}{*}{ LOS } & \multirow{3}{*}{\begin{tabular}{|c|} 
delay \\
reduction \\
$\%$
\end{tabular}} & \multirow{3}{*}{$\begin{array}{c}\text { capacity } \\
\text { improvement } \\
\%\end{array}$} \\
\hline & \multirow{2}{*}{$\begin{array}{c}\text { Cycle } \\
\text { Time } \\
\text { (sec) } \\
\text { C }\end{array}$} & \multicolumn{4}{|c|}{ Effective Green Time (sec) } & & & & \multirow{2}{*}{$\begin{array}{c}\text { Cycle } \\
\text { Time } \\
\text { (sec) } \\
\text { C }\end{array}$} & \multicolumn{4}{|c|}{ Effective Green Time (sec) } & & & & & \\
\hline & & g1 & $g 2$ & g3 & $g 4$ & & & & & g1 & g2 & g3 & $g 4$ & & & & & \\
\hline $7: 00-9: 00$ & 196 & 46 & 63 & 37 & 50 & 4395 & 130 & $\mathrm{~F}$ & 185 & 39 & 60 & 42 & 44 & 4946 & 90 & $\mathrm{~F}$ & 31 & 13 \\
\hline $9: 00-11: 00$ & 196 & 46 & 63 & 37 & 50 & 4395 & 116 & $\mathrm{~F}$ & 152 & 30 & 55 & 34 & 33 & 4885 & 67 & E & 42 & 11 \\
\hline $11: 00-13: 00$ & 196 & 46 & 63 & 37 & 50 & 4395 & 151 & $\mathrm{~F}$ & 152 & 34 & 60 & 28 & 30 & 4879 & 80 & $\mathrm{~F}$ & 47 & 11 \\
\hline $13: 00-15: 00$ & 196 & 46 & 63 & 37 & 50 & 4395 & 88 & $\mathrm{~F}$ & 112 & 27 & 37 & 23 & 25 & 4942 & 48 & D & 45 & 12 \\
\hline $15: 00-17: 00$ & 196 & 46 & 63 & 37 & 50 & 4395 & 133 & $\mathrm{~F}$ & 169 & 39 & 60 & 35 & 35 & 4890 & 85 & $\mathrm{~F}$ & 36 & 11 \\
\hline $17: 00$ - 19:00 & 196 & 46 & 63 & 37 & 50 & 4395 & 151 & $\mathrm{~F}$ & 162 & 34 & 60 & 34 & 34 & 4884 & 94 & $\mathrm{~F}$ & 38 & 11 \\
\hline $19: 00-21: 00$ & 196 & 46 & 63 & 37 & 50 & 4395 & 104 & $\mathrm{~F}$ & 139 & 33 & 48 & 30 & 28 & 4869 & 62 & $E$ & 40 & 11 \\
\hline $21: 00-23: 00$ & 196 & 46 & 63 & 37 & 50 & 4395 & 82 & $\mathrm{~F}$ & 91 & 20 & 29 & 22 & 20 & 4888 & 37 & C & 55 & 11 \\
\hline
\end{tabular}


To better visualization, the difference control delay, is illustrated in the following between the current and the GA-based average graph in Figure 8 below:

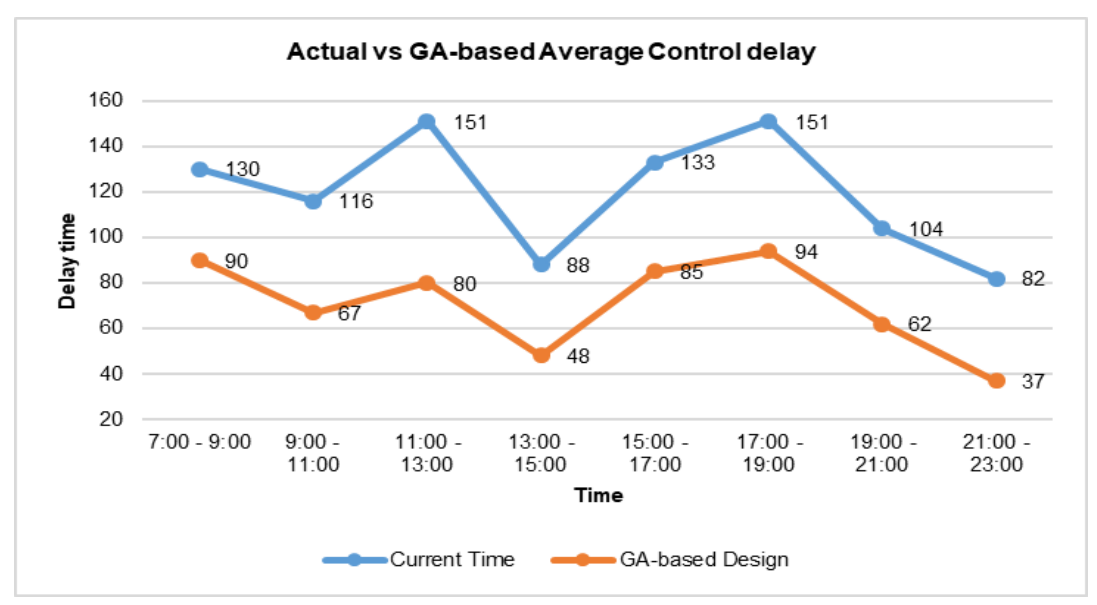

Figure (8): Average Control Delay at Hadyab Intersection before and after Optimization

Table (7): Signal timing of Shahidan Intersection before and after Optimization

\begin{tabular}{|c|c|c|c|c|c|c|c|c|c|c|c|c|c|c|c|c|c|c|}
\hline \multirow{3}{*}{ Time Group } & \multicolumn{5}{|c|}{ Current Time } & \multirow{3}{*}{$\begin{array}{c}\text { max. } \\
\text { Capacity } \\
\text { (veh) }\end{array}$} & \multirow{3}{*}{$\begin{array}{c}\text { avg. } \\
\text { Delay } \\
\text { (sec/veh) }\end{array}$} & \multirow{3}{*}{ LOS } & \multicolumn{5}{|c|}{ GA- based Design } & \multirow{3}{*}{$\begin{array}{c}\text { max. } \\
\text { Capacity } \\
\text { (veh) }\end{array}$} & \multirow{3}{*}{$\begin{array}{c}\text { avg. } \\
\text { Delay } \\
\text { (sec/veh) }\end{array}$} & \multirow{3}{*}{ LOS } & \multirow{3}{*}{$\begin{array}{c}\text { delay } \\
\text { reduction } \\
\%\end{array}$} & \multirow{3}{*}{$\begin{array}{c}\text { capacity } \\
\text { improvement } \\
\%\end{array}$} \\
\hline & \multirow{2}{*}{$\begin{array}{c}\text { Cycle } \\
\text { Time } \\
\text { (sec) } \\
\text { C }\end{array}$} & \multicolumn{4}{|c|}{ Effective Green Time (sec) } & & & & \multirow{2}{*}{$\begin{array}{c}\text { Cycle } \\
\text { Time } \\
\text { (sec) } \\
\text { C }\end{array}$} & \multicolumn{4}{|c|}{ Effective Green Time (sec) } & & & & & \\
\hline & & $g 1$ & g2 & g3 & g4 & & & & & $g 1$ & g2 & g3 & g4 & & & & & \\
\hline 7:00 - 9:00 & 200 & 60 & 40 & 52 & 48 & 3156 & 82 & $\mathrm{~F}$ & 94 & 28 & 15 & 20 & 31 & 3232 & 33 & C & 60 & 2 \\
\hline $9: 00-11: 00$ & 200 & 60 & 40 & 52 & 48 & 3156 & 84 & $\mathrm{~F}$ & 124 & 42 & 15 & 36 & 31 & 3298 & 48 & D & 43 & 4 \\
\hline $11: 00-13: 00$ & 200 & 60 & 40 & 52 & 48 & 3156 & 104 & $\mathrm{~F}$ & 173 & 44 & 37 & 56 & 36 & 3209 & 75 & $\mathrm{E}$ & 28 & 1 \\
\hline $13: 00-15: 00$ & 200 & 60 & 40 & 52 & 48 & 3156 & 73 & $E$ & 90 & 28 & 15 & 25 & 22 & 3216 & 33 & C & 55 & 2 \\
\hline $15: 00-17: 00$ & 200 & 60 & 40 & 52 & 48 & 3156 & 76 & $E$ & 100 & 30 & 15 & 27 & 28 & 3246 & 37 & D & 51 & 3 \\
\hline $17: 00$ - 19:00 & 200 & 60 & 40 & 52 & 48 & 3156 & 75 & $E$ & 93 & 29 & 16 & 27 & 21 & 3205 & 42 & D & 44 & 2 \\
\hline $19: 00-21: 00$ & 200 & 60 & 40 & 52 & 48 & 3156 & 72 & $E$ & 82 & 26 & 15 & 25 & 16 & 3185 & 29 & C & 60 & 1 \\
\hline $21: 00-23: 00$ & 200 & 60 & 40 & 52 & 48 & 3156 & 67 & E & 73 & 19 & 15 & 18 & 21 & 3198 & 24 & C & 64 & 1 \\
\hline
\end{tabular}

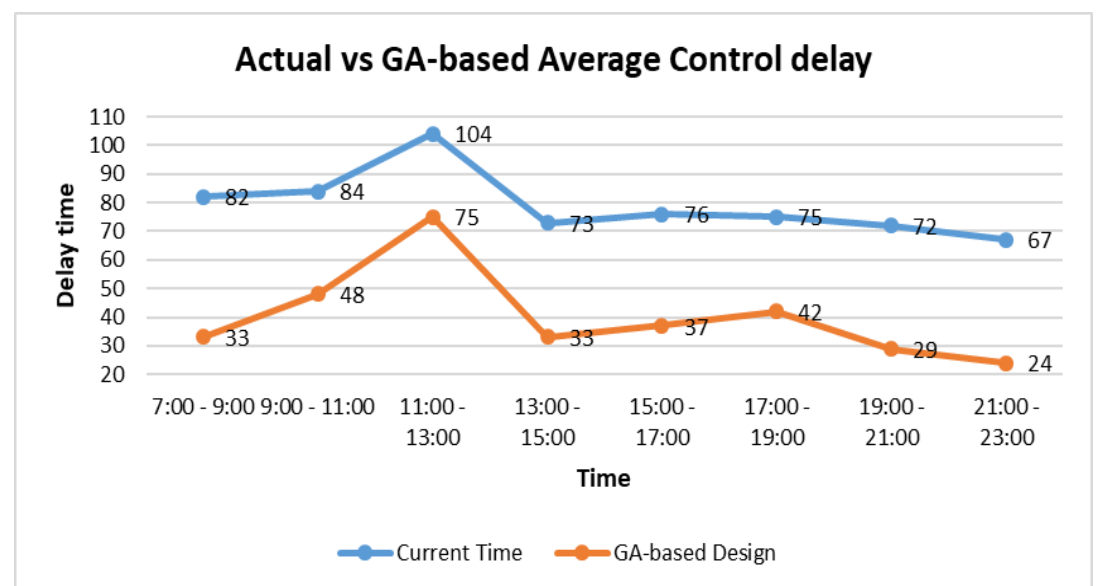

Fig. (9): Average Control Delay of Shahidan Intersection before and after Optimization

Shahidan Intersection, due to its location in the City Center near to the Bazaar of the City naza.ghani@tiu.edu.iq; botan@epu.edu.iq

${ }^{1}$ Corresponding author: College of Engineering, Tishik International University, Kurdistan Region, Iraq. 
has different peak hours, which starts mostly in the morning and extends to midday. Delay is improved from $28 \%$ to up to $64 \%$. The LOS improved constantly according to the traffic demand. During the time lag (11:00-13:00) the LOS before and after the optimization remained unchanged at $\mathrm{F}$ although the delay is reduced by $28 \%$ and this is because of the high traffic volume. Meanwhile, the rest of the time lags upgraded from LOS $\mathrm{F}$ to $\mathrm{C}$ and $\mathrm{D}$ according to the traffic condition. The capacity could be improved by the optimization in the signal timing by $2 \%$, which means that the intersection can serve a minimum of 30 to 140 vehicles more than before.

The optimized result could lead to a reduced travel time due to improvements in delay and consequently this will raise the comfortability of the drivers and the passengers. This will enhance the quality of both the environment and flow characteristic at the intersection (Pop, 2018).

\section{CONCLUSIONS}

In a continuous developing city, as Erbil were the population and number of vehicles are rising with an annual rate of approximately 17 percent, the roads and especially the intersections needs to be managed, since through unorganized traffic intersection the delay increases and this leads to traffic jams.

One of the techniques to solve this problem is to optimize the traffic signal timing, as the intersections are already designed. Therefore, optimization can be done in several methods, but the most effective method is Genetic Algorithms (GA). As it is used for almost three decays. It could provide sensational results for every traffic mode. In this study, it is used for dynamic pretimed traffic mode. By using the optimum cycle length and green time for each time group.

Through the optimization the signal timing, the quality of the intersections improved by naza.ghani@tiu.edu.iq; having a massive reduction in delay as well as increase in the capacity in the intersection. Delay could decrease with an average reduction of 42 which means that delay could be reduced by an average of $49 \mathrm{sec}$ per vehicle for Hadyab intersection and for Shahidan intersection the average reduction is $51 \%$ which means that 39 sec per vehicle. In addition to that, the capacity of the intersection could be improved averagely by $2 \%$ to $11 \%$. This concludes that, various signal timing based on traffic flow and characteristics of the intersection can improve the quality of the intersection. For this reason, optimization is essential for the quality of the intersections. Every intersection should be optimized in order to improve the quality of life as well as the economy.

\section{REFERENCES}

DECISION, R. O. (2015). Federal Highway Administration. US Department ofTransportation, Washington, $D C$.

Foy, M. D., Benekohal, R. F., \& Goldberg, D. E. (1992). Signal timing determination using genetic algorithms. Transportation Research $\operatorname{Record}(1365), 108$.

Garber, N. J., \& Hoel, L. A. (2014). Traffic and highway engineering: Cengage Learning.

Haupt, R. L., \& Ellen Haupt, S. (2004). Practical genetic algorithms.

Holland, J. (1975). An efficient genetic algorithm for the traveling salesman problem. European Journal of Operational Research, 145, 606617.

Jiang, J., Tan, H., Zhang, J., Ran, B., \& Tang, F. (2019). A Signal Control Scheme Optimization Method for K-Shaped Intersections Using Genetic Algorithm CICTP 2019 (pp. 30403051).

Kesur, K. B. (2009). Advances in genetic algorithm optimization of traffic signals. Journal of botan@epu.edu.iq 
Transportation Engineering, 135(4), 160-173.

Kesur, K. B. (2014). Optimization of mixed cycle length traffic signals. Journal of advanced transportation, 48(5), 431-442.

Manual, H. C. (2010). HCM2010. Transportation Research Board, National Research Council, Washington, DC, 1207.

Pop, M.-D. (2018). Traffic lights management using optimization tool. Procedia-social and behavioral sciences, 238, 323-330.

Sharma, B., \& Kumar, S. (2019). Delay optimization using genetic algorithm at the road intersection. International Journal of Information Retrieval Research (IJIRR), 9(2), $1-10$.

Sivanandam, S., \& Deepa, S. (2008). Genetic algorithm implementation using matlab Introduction to Genetic Algorithms (pp. 211262): Springer.

Whitley, D. (2001). An overview of evolutionary algorithms: practical issues and common pitfalls. Information and software technology, 43(14), 817-831. 